\title{
A TUTELA PENAL DO CONSUMIDOR SOB O ENFOQUE DOS DIREITOS À SAÚDE E À SEGURANÇA*
}

\author{
Amanda Rodrigues da Cruz**
}

\begin{abstract}
RESUMO: A Constituição Federal de 1988 estabeleceu a defesa do consumidor como garantia fundamental, a qual inclui a tutela penal do consumidor. Algumas condutas foram tipificadas na legislação esparsa como sendo crimes, dado o alto grau de ofensividade à pessoa humana. Serão analisadas neste trabalho as espécies delituosas que mais ofendem o direito à saúde e segurança do consumidor, nas esferas individual e coletiva. Assim, o legislador reservou também ao braço armado do Estado a salvaguarda dos direitos do consumidor, especialmente no que diz respeito à saúde e segurança. Estes direitos devem ser seguramente resguardados. A proteção efetiva da incolumidade física do consumidor, bem como formas de previnir e reprimir estes delitos serão desenvolvidos neste trabalho, além de serem apresentadas situações fáticas envolvendo o tema.
\end{abstract}

PALAVRAS-CHAVE: Crime. Proteção. Saúde. Consumidor.

ABSTRACT: The Federal Constitution of 1988 established the consumer defense as a fundamental guarantee, which includes the criminal care of the consumer. Some behaviors were tipified at the legistlation as being crimes, due to the high level of ofensivity to the human person. It will be analysed at this paper the delictuous types which more offend the right to health and safety of the consumer, at the coletive and individual scopes. Therefore, the legislator reserved to the armed branch of the State the protection of consumer's rights, specially referring to health and safety. These rights must be highly protected. The effective protection of physical incolumity of the consumer, as well as ways of prevention and repression of these delicts are developed in this paper and are also presented fact situations involving the theme.

KEY-WORDS: Crime. Protection. Health. Consumer.

"Trabalho desenvolvido para a apresentação na VI Semana Acadêmica de Direito da Universidade Federal de Santa Maria.

*** Acadêmica do $6^{\circ}$ Semestre do Curso de Direito Diurno da Universidade Federal de Santa Maria.

\section{INTRODUÇÃO}

$\mathrm{Na}$ contemporaneidade, vive-se um verdadeiro caos nas relações sociais e econômicas. Isto vem acontecendo como reflexo direto da globalização. Os impactos do alto desenvolvimento da tecnologia e do intercâmbio de culturas e informações refletem diretamente no comportamento humano, especialmente no que concerne ao âmbito econômico e mercadológico. É o sentimento de usura que vem se manifestando crescentemente nos fornecedores de produtos o serviços. Esta ambição, pois, faz com que a preocupação com a saúde e segurança do consumidor sejam colocadas em segundo plano, em detrimento da maior lucratividade. A partir disso, a dignidade da pessoa humana do consumidor, seu bem-estar e sua qualidade de vida, deixam de estar entre as principais metas dos fornecedores de produtos e serviços. $\mathrm{O}$ fornecedor não tem se importado com os efeitos que o seu produto ou serviço causará à pessoa que o adquiriu e dele irá usufruir.

Não obstante, com o desenvolvimento da mídia eletrônica e a propagação desenfreada da informação, as ofertas de produtos e serviços tem atingido um número crescente de pessoas. Isto faz com que, cada vez mais, haja aderência aos novos bens de 
consumo, quer sejam essenciais, quer sejam supérfluos. É a realidade do consumismo, o qual cresce gradativamente na sociedade, muitas vezes com o intuito de alcançar status social. Diante disso, é certo que os consumidores olvidam a atenção com os bens que adquirem, deixando-se enganar facilmente, sofrendo, posteriormente, graves conseqüências, especialmente em sua saúde e segurança.

Analisar-se-á neste trabalho os riscos efetivos que a produção e o consumo em massa geram à saúde e segurança da coletividade. Serão estudados os delitos mais recorrentes contra as relações de consumo, bem como o amparo legal que o consumidor encontra frente a estes delitos. Assim, será possível obter uma percepção, mesmo que sucinta, da complexidade das relações de consumo e da proteção penal do consumidor, prevista pela legislação brasileira, bem como dos delitos contra ele existentes nos tempos atuais.

\section{LEGISLAÇÃO GARANTIDORA DA TUTELA PENAL DO CONSUMIDOR}

Os crimes contra as relações de consumo existem há muito tempo no Brasil, o próprio diploma penal já os previa em dispositivos esparsos. Não obstante, em meados de 1950, surge no ordenamento jurídico brasileiro a Lei da Economia Popular - Lei 1521/51. Este regulamento, embora timidamente, já traz alguma previsão de sanção na esfera penal aos delitos contra o consumo.

Posteriormente, com a democratização do pensamento jurídico e, a partir da entrada em vigor da Constituição Republicana de 1988, nasceu uma mobilização do legislador para que fosse criada uma legislação específica de plena proteção e defesa ao consumidor nas esferas civil, administrativa e penal. Em seu art. $5^{\circ}$, inciso XXXII, a Carta Magna já previa a proteção e defesa ao consumidor. Além disso, o art. 170, inciso V, da Constituição Federal dispõe a defesa do consumidor como parâmetro para a ordem econômica. No entanto, como se observará deste trabalho, a proteção ao consumidor não resume-se tão somente à esfera econômica. O consumidor é amparado, ainda, pelo art. $6^{\circ}$ desta Constituição, que dispõe os direitos à saúde e à segurança como direitos sociais. Seriam os direitos da segunda geração (MORAES, 2006). De igual forma, o art. 48 do ADCT da mesma Carta Republicana constituiu um prazo de 120 dias, a partir da promulgação desta Carta, para que fosse elaborado o Código de Defesa do Consumidor.

Com isso, na década de 90, o consumidor passou a ter garantidamente resguardados seus direitos por legislação específica, qual seja, o Código de Defesa do 
Consumidor. No entanto, a Lei 8.078/90 não é a única norma onde se encontram elencadas infrações penais contra o consumidor. O CDC não as esgota no rol dos arts. 61 a 80. Complementando o CDC, a lei 8.137/90 define, além de crimes contra a ordem tributária e econômica, crimes contra as relações de consumo.

Aliado ao alargamento da proteção ao consumidor, começou-se a elencar, não só através da lei como também por via doutrinária, a saber, Claudia Lima Marques (2006), princípios específicos para que o intérprete da lei os utilizasse de forma a proporcionar a devida e efetiva proteção ao consumidor. Diante disso, é possível afirmar que todos os princípios de proteção ao consumidor decorrem de um único princípio, qual seja, o da dignidade da pessoa humana. Este princípio é fundamental para a manutenção do Welfare State (Estado de direito), já que deve ser utilizado nas relações de consumo para que se atinja a finalidade de equilibrar a relação entre fornecedor e consumidor vulnerável (art. $4^{\circ}$, inciso I do CDC) e hipossuficiente (art. $6^{\circ}$, inciso VIII do CDC), previnindo que o consumidor seja ofendido, não somente enquanto consumidor, mas também como pessoa humana sendo vítima de infrações penais contra as relações de consumo.

A proteção especial ao consumidor se faz fundamental nos tempos hodiernos, onde há um sentimento de que o ter é maior que o ser. Com isso, muitos fornecedores de produtos e serviços passam a se utilizar dos mais astutos estratagemas para obter lucro em detrimento da dignidade do consumidor como pessoa humana. Isto conduz a propagação dos delitos contra o consumidor e efeitos danosos à ordem pública. Atentase gradativamente à saúde, ao direito à informação, à integridade, aproveitando-se da vulnerabilidade do consumidor, em grande parte dos casos, sob dolo antecedente.

\section{CLASSIFICAÇÃO DOS DELITOS CONTRA AS RELAÇÕES DE CONSUMO}

A proteção efetiva às relações de consumo engloba a prevenção contra danos iminentes ao consumidor, parte mais vulnerável desta relação jurídica, que expõem a perigo bens juridicamente relevantes. Estes bens devem ser protegidos de todo e qualquer dano, mesmo que iminente. Seriam estes os crimes de perigo abstrato, ou seja, dispensam comprovação de que aquela ação ou omissão do fornecedor venha a ferir direito do consumidor. Considerada a vulnerabilidade do consumidor, este perigo é perceptível juris et jure aos olhos do intérprete da norma e do aplicador da lei. A exemplo disso pode-se citar situações como a exposição à venda de carnes em estado de decomposição, porém "maquiadas" em açougues, mesmo que o consumidor não realize 
o contrato de consumo; bem como um laboratório que, ao comercializar um medicamento, não esclarece em sua bula que o medicamento é abortivo, trazendo conseqüências fatais à gestante que o consome. Faz-se, portanto, a análise do risco efetivo de lesão a direito do consumidor. Este tipo de delito se consuma, pois, com a criação de perigo de dano ao consumidor. Estes crimes afetam diretamente as relações de consumo, são crimes próprios de consumo. Isto significa que os seus sujeitos são necessariamente fornecedor (sujeito ativo) e consumidor (sujeito passivo), facilmente identificáveis.

Os crimes formais, por sua vez, são aqueles crimes que pressupõem uma conduta aliada a um resultado. Mesmo que o resultado não seja consumado, mas havendo uma ligação entre conduta e resultado, o delito continua sendo formal. Pode existir na forma tentada ou consumada.

Além disso, existem os crimes de mera conduta. Estes delitos consumam-se, como o nome diz, com a simples ação ou omissão do sujeito ativo, não estando ela necessariamente ligada a um resultado ou possível resultado.

A doutrina se divide entre esses dois entendimentos. Parte da doutrina entende que estes conceitos se confundem, a saber, Bitencourt (2004, p. 195): "Na verdade, temos dificuldade de constatar com precisão a diferença entre crime formal e de mera conduta". Neste trabalho, enetende-se, pois, que o crime de mera conduta se consuma com a simples ação ou omissão do ofensor de determinado bem jurídico.

\section{SUJEITOS DOS DELITOS}

Nos crimes diretamente ligados às relações de consumo, os sujeitos são bem definidos: fornecedor, sendo o sujeito ativo, e consumidor como sujeito passivo. Esses delitos, em sua maioria, encontram-se tipificados na legilsação consumerista, tal qual, o Código de Defesa do Consumidor, como a Lei 1521/51, além da Lei 8137/90.

Existem delitos que estão indiretamente ligados às relações de consumo. São os crimes que Antônio Herman V. Benjamin (2006) classifica como impróprios. Estes delitos, na sua essência, não foram tipificados com o fim de proteger as relações de consumo. Estão dispostos em outros diplomas que não o CDC. Dentre eles, podemos citar o crime de estelionato (art. 171 do Código Penal), bem como os delitos dos artigos 272 e 273 do Código Penal, crimes contra a saúde pública sendo considerados, inclusive, delitos hediondos pela Lei 8.072/90. Pode-se auferir, com isso, que os sujeitos nem sempre são fornecedor e consumidor. A partir disso, tem-se a ampliação de 
proteção aos direitos do consumidor na esfera criminal, a qual não se limita apenas aos delitos previstos pela lei consumerista.

Deste modo, para fins de informação e conseqüente prevenção destes delitos, é imprescindível que neste trabalho se aborde algumas espécies destes delitos. Buscar-seá esclarecer, ainda, quais os direitos fundamentais do consumidor são feridos por estas infrações penais.

\section{ESPÉCIES MAIS RECORRENTES DE DELITOS DE CONSUMO ANTE OS DIREITOS À SAÚDE E À SEGURANÇA}

\subsection{RELATIVOS AO DEVER DE INFORMAÇÃO}

A Lei 8137/90, em seu art. $7^{\circ}$, inciso IX tipifica como crime a conduta de "vender, ter em depósito para vender ou expor à venda ou, de qualquer forma, entregar matéria-prima ou mercadoria, em condições impróprias ao consumo”. Este dispositivo surgiu posteriormente ao veto do Presidente Fernando Collor de Mello ao art. 62 do $\mathrm{CDC}$, que tinha teor muito semelhante ao disposto neste art. $7^{\circ}$, inciso IX. Esta, porém, é uma norma penal em branco, que foi encontrar apoio no art. $18, \S 6^{\circ}$ do CDC. Este dispositivo esclarece quais são os produtos considerados impróprios para o consumo: produtos em que o prazo de validade esteja vencido, os que se encontrem deteriorados, alterados, adulterados, nocivos à vida ou à saúde; ou em desacordo com normas regulamentares de fabricação, distribuição ou apresentação, ou ainda que, por qualquer motivo, apresente-se inadequado ao fim a que se destina.

No caso em tela, são recorrentes os atentados à saúde e à dignidade da pessoa humana do consumidor. A exemplo disso pode-se citar a exposição à venda de medicamentos com prazo de validade vencido, expondo a risco a saúde do consumidor como sujeito supraindividual. Ou seja, o dano causado pela omissão de uma informação essencial acerca do produto não se limita ao consumidor individualizado, mas também atinge uma coletividade de consumidores. É de extrema importância referir que muitas pessoas usam medicamentos controlados para determinada patologia, tais quais o diabetes, tendo que depender, recorrentemente, da boa-fé dos fornecedores destes remédios. Contudo, fornecedores expõem a risco a saúde da coletividade como se ignorassem a gravidade dos vícios do produto. Não raro, fornecedores alegam que o material exposto à venda está nas prateleiras só para preencher o espaço vazio. Alegação que não procede e, mesmo que fosse verídica, é uma ameaça a saúde do 
consumidor, configurando o elemento subjetivo do tipo, qual seja, o dolo, mesmo que eventual.

Outra situação comum é a exposição de alimentos em gôndolas de supermercados que estejam, por quaisquer dos motivos expostos na lei, impróprios para o consumo. Alimentos que compõem a dieta básica nutricional, a saber, laticínios, carnes, grãos, massas e pães, freqüentemente encontram-se nos locais de venda em condições impróprias para o consumo. É comum encontrar feijão perfurado por pequenos animais que consomem o grão dentro da própria embalagem, como também larvas em pacotes de massas, dentre outros disparates.

No que se refere ao alimento carne, existe um grande problema quanto ao abate de animais. Não raro, estas práticas acontecem de maneira clandestina, sem as devidas condições de higiene e sanitarização. Muitas vezes o sacrifício de animais não é feito sob a supervisão de um veterinário, condição regulamentar para o abate. Não obstante, também é recorrente o problema do armazenamento das carnes ${ }^{1}$. Em muitos depósitos as carnes não estão sob a temperatura idônea para sua conservação. Os fornecedores utilizam muitos refrigeradores antigos, que não têm mais a potência de resfriar os cortes na temperatura devida para que se mantenha saudável o alimento. Entretanto, isto não se torna óbice para o fornecedor de má-fé comercializar os cortes de carne, já que, nos mercados e açougues, os comerciantes costumam "maquiar" a carne deteriorada, retirando os pedaços já podres e mantendo o pedaço que ainda tem aparência de saudável para exposto à venda.

A pena prevista para este delito é de detenção de 2 a 5 anos, ou multa. Por se tratar de uma relação econômica, teve êxito o legislador ao dar a opção ao aplicador da norma de aplicar uma sanção de natureza pecuniária.

Os arts. 63 e 64 do CDC, por sua vez, referem-se a delitos de omissão. O crime do art. 63 configura-se quando o fornecedor deixa de prestar esclarecimentos sobre a periculosidade do produto antes de o colocá-lo em circulação. Ora, todo o fornecedor deve conhecer seus produtos ou serviços, e prestar informações ostensivas na embalagem ou meio de veiculação do produto ou serviço sobre sua nocividade ou periculosidade.

Este delito existe nas formas culposa e dolosa. É culposo quando o fornecedor é negligente, deixando de prestar informações. Já na forma dolosa, o fornecedor age com

${ }^{1}$ MINISTÉRIO PÚBLICO, Rio Grande do Sul. Operação Conjunta de Fiscalização de Qualidade de Alimentos em Dom Pedrito. Disponível em: http://www.mp.rs.gov.br/consumidor/noticias/id12138.htm Acesso em 09 out. 2007. 
dolo direto. Deixa de dar informações conscientemente, a fim de não obstaculizar a futura distribuição e venda do produto ou serviço, sendo que, se o consumidor souber de seus riscos inerentes, pode vir a deixar de adquirir o produto. A exemplo de produtos suscetíveis de omissão de dizeres sobre seus riscos estão os fogos de artifício, a serra elétrica, produtos abrasivos em geral, bem como produtos de limpeza compostos de produtos altamente intoxicantes. A sanção para este delito é de detenção de 6 meses a 2 anos e multa. Na sua forma culposa, a pena é de detenção de 1 a 6 meses ou multa.

De acordo com o art. 64, outrora, o fornecerdor omite informações a respeito da periculosodade do produto posteriormente à sua colocação no mercado. É a chamada periculosidade adquirida (BENJAMIN, 2006, p. 904), a qual é indevida e aparece no produto depois deste já estar circulando para comercialização. O fornecedor silencia a respeito de algum vício, já que as vendas estão indo bem, por exemplo. Isto configura o dolo eventual. O fornecedor assume o risco ao não informar. Sabe do risco mas mantém-se inerte diante disso.

Em seu parágrafo único, o art. 64 prevê punição para os fornecedoes que se omitem quanto ao Recall. Isto consiste na conduta de o fornecedor retirar do mercado, de imediato, produto nocivo à segurança do fornecedor. Esta retirada do mercado de produtos que ameaçem a incolumidade físico-psíquica do consumidor pode ser tanto determinada por órgão oficial, quanto voluntária do fornecedor. Esta última, quando acontece, mostra que o fornecedor cumpre sua função de previnir o consumidor contra os acidentes de consumo, conforme os arts. $6^{\circ}$, inciso VI e 10, caput, da Lei 8078/90. A pena cominada para este delito é de detenção de 6 meses a 2 anos e multa.

Além do dever da prevenção, as sanções impostas pelos arts. 63 e 64 do CDC vêm reprimir as condutas de fornecedores que não cumprem com seu dever de informação, princípio básico da legislação consumerista. Os arts. $8^{\circ}$, parágrafo único, $9^{\circ}$ e 10, bem como o art. $6^{\circ}$, inciso III e o art. 31, todos do Código de Defesa do Consumidor, explicitam a informação, com transparência e clareza, como dever do fornecedor e direito básico do consumidor.

Ora, como consequência inevitável do descumprimento do dever de informação nas relações de consumo, surge a gritante ameaça aos direitos básicos à saúde e a segurança previstos pela Constituição Federal de 1988.

\subsection{REFERENTES À INCOLUMIDADE FÍSICA DO CONSUMIDOR}


Esta análise será feita sob os reflexos da interpretação do art. $6^{\circ}$, inciso I do CDC, o qual define a vida, a saúde e a segurança como direitos básicos do consumidor.

No art. 65 da lei de proteção ao consumidor, existe a disposição de um delito que alude a perigos inerentes aos serviços prestados pelo fornecedor que age contra determinação de autoridade competente. Note-se que estes riscos não se resumem aos riscos esperados da atividade, trata-se de nocividade gerada pelo fornedor por não tomar a devida precaução e não utilizar de equipamentos de segurança e lançar mão de cuidados mínimos. É uma espécie de periclitação da vida e da saúde.

Este perigo cerca algumas atividades tais quais a dedetização, desratização (FILOMENO, 2007, p. 104), saltos de "bungjump", serviços promovidos por empresas de esportes radicais para amadores, a saber, o rapel, o rafting e a escalada.

No parágrafo único do art. 65 ora analisado, está prescrito, ainda, que as penas referentes a este delito podem ser cumuladas com as de lesões corporais e homicídio. Parte da doutrina (BENJAMIN, 2006) considera que os delitos supracitados absorvem o delito do art. 65 do $\mathrm{CDC}$, quando são cometidos simultaneamente, por apresentarem uma maior gravidade, muito embora esta não seja a doutrina mais aceita. O entendimento mais adequado é o de que as penas cumulam-se. Em virtude da natureza do delito praticado, então, pode-se determinar o juízo competente para o ajuizamento da ação penal, quais sejam, os Juizados Especiais Criminais (Lei 9.099/95), caso o delito seja cometido na forma de seu caput ou seguido de lesões corporais leves ou culposas, a Justiça Comum para lesões corporais ou lesões corporais graves ou, ainda, seguida de morte, ou homicídio culposo ou, ainda, o Tribunal do Júri em caso de homicídio doloso (art. 74 e 76 do Código de Processo Penal).

Não obstante a tutela individual retrocitada, não se pode afastar a hipótese de uma ação penal coletiva caso o delito de perpetue contra uma coletividade de pessoas. Adiante, analisaremos mais profundamente este aspecto.

Ademais, conforme Filomeno (2007), o art. 65 do CDC trata-se de norma penal em branco, uma vez que requer complementariedade de determinação de autoridade competente acerca do delito o qual o caput refere.

Os delitos contra a integridade física e psíquica do consumidor não se esgotam no CDC. O próprio diploma penal prevê delitos contra a saúde. Todavia, os crimes contra o consumidor previstos pelo Código Penal, vêm acompanhados de sanções mais rigorosas do que as previstas pela legislação consumerista. O legislador criminal postulou penas de reclusão ao infrator destes dispositivos. Isto ocorre dado o cunho 
preventivo, repressivo e retributivo que, pelo intuito o qual este Código foi criado, deve ser efetivo, até mesmo mais do que a legislação criminal extravagante.

Os artigos 272 e 273 do Código Penal são considerados crimes hediondos pela Lei 8.072/90 (Lei dos Crimes Hediondos). As condutas neles descritas remetem à corrupção, adulteração, falsificação de alimentos e produtos destinados a fins terapêuticos ou medicinais, respectivamente. Nestes crimes é explícita a ofensa aos bens jurídicos vida, saúde e segurança, sendo que a coletividade está exposta a sofrer danos à sua incolumidade física.

No que concerne aos alimentos, é inegável a nocividade daqueles destinados especialmente para diabéticos, por exemplo, e que sofrem alterações na sua essência, podendo gerar, em certos casos, até mesmo a morte do consumidor.

Além disso, quanto aos medicamentos, é relevante fazer alusão neste trabalho do ocorrido no Brasil na década de 90 que gerou forte celeuma, por ter atingido um número indeterminado de pessoas, qual seja, a famigerada "pílula de farinha", fato determinante para o legislador incluir o art. 273 do Código Penal no rol dos crimes hediondos da Lei 8.072/90 (NUCCI, 2007, p. 602). O comprimido Microvilar sofreu uma alteração em sua substância essencial, a qual dava à pílula o seu efeito contraceptivo. No lugar desta substância, foi colocada substância inócua a evitar a gravidez. Entretanto, isto aconteceu com alguns lotes do medicamento, o que foi suficiente para atingir uma coletividade de consumidoras. Este fato atentou diretamente contra a saúde pública, ferindo o planejamento familiar de muitas famílias que sequer tinham condições de criar um filho. Em virtude disso, o Judiciário recebeu incontáveis ações de cidadãos que tiveram seu o direito de evitar a gravidez violado (FILOMENO, 2007).

Os exemplos acima expostos configuram os elementos dos delitos dos arts. 272 e 273 do Código Penal, o que possibilita a propositura de uma ação penal pública, meio em que se buscará o devido julgamento do fato a fim de uma resposta jurisdicional adequada.

Os arts. 274, 275, 276, 277 e 278 do mesmo diploma legal referem-se a substâncias nocivas adicionadas a alimentos ou medicamentos. São delitos em que o sujeito ativo, sob o ânimo do dolo, ludibria o consumidor causando dano à saúde e à segurança do consumidor, mesmo que de forma potencial.

\subsection{RELATIVOS À PUBLICIDADE LESIVA AO CONSUMIDOR}


O Código de Defesa do Consumidor classifica a oferta publicitária do fornecedor, quando veiculada de forma lesiva, em enganosa e abusiva (art. 67). A publicidade enganosa é aquela que omite informações ou veicula em proporções midiáticas informações inverídicas ou ilusórias sobre o produto ou serviço. Isto é, o fornecedor enseja o consumidor a adquirir o bem, por meio de falsa afirmação, mesmo que isto possa lhe resultar em perigo. A modalidade abusiva, por seu turno, se caracteriza pela conduta do fornecedor de se aproveitar da falta de instrução, esclarecimento, conhecimento técnico, ingenuidade das crianças e, até mesmo, de idosos para lhes iludir a respeito da qualidade de um produto ou serviço, a fim de obter lucro vendendo em grande escala o seu produto ou serviço.

O art. 68 da Lei 8.078/90 trata especificamente da publicidade lesiva à saúde e à segurança do consumidor, as quais fazem parte de nosso tema.

Não obstante, vale mencionar que no Código Penal encontram-se delitos que não são essencialmente contra as relações de consumo. Apesar disso, os tipos dos arts. 171 (estelionato) e 175 (fraude contra o comércio) seguidamente são praticados por fornecedores em detrimento de consumidores.

No cotidiano dos consumidores, não raro ocorrem delitos desta espécie. $\mathrm{Na}$ segunda metade do ano de 2007, no estado do Rio Grande do Sul, vendedores falaciosos percorriam as ruas das cidades indo de porta em porta oferecer almofadas e esteiras terapêuticas, dizendo-as "milagrosas".

Um inquérito foi instaurado para investigar possível publicidade enganosa e prática comercial abusiva em relação à comercialização, pelas empresas, dos aparelhos que não produziriam os efeitos informados. Segundo reclamações, vindas de vários municípios do Rio Grande do Sul, vendedores das empresas, em visitas às residências dos consumidores lesados, ofereciam colchões e almofadas fisioterápicas e ortopédicas que possuiriam propriedades terapêuticas. As queixas ainda mencionam a total inocuidade dos produtos (MINISTÉRIO PÚBLICO, Rio Grande do Sul. Ações pedem suspesão da venda de almofadas. Disponível em: http://www.mp.rs.gov.br/consumidor/noticias/id12249.htm. Acesso em 08 out. 2007).

Entretanto, estes vendedores ofereciam o produto somente a idosos, descontando o valor da compra de seus benefícios previdenciários. Aproveitando-se da fragilidade da saúde de muitos, estes fornecedores informavam aos seus consumidores que o uso de tal 
produto possibilitaria a cura de qualquer problema de saúde. De tal maneira, muitos idosos acabaram adquirindo os produtos a preços exorbitantes, muito além do valor usual destes produtos, sendo vítimas desta quadrilha.

Também é comum a oferta de compostos emagrecedores milagrosos, tônicos para crescer cabelos, estimulates sexuais sem o devido esclarecimento a respeito dos reais efeitos do produto (FILOMENO, 2007). Esta prática dos fornecedores de enaltecer exacerbadamente a qualidade do produto é conhecida como dolus bonus. Tal conduta consiste em fazer uma afirmação falsa a respeito do produto, iludindo o consumidor ao agregar vantagens inexistentes ao produto ou serviço oferecido com o intuito de vender o produto.

Para a conduta do art. 68 do CDC a sanção, pois, é de detenção de 6 meses a 2 anos e multa.

É relevante para este estudo que se faça a análise do tipo do art. 70 da Lei 8.078/90. Este delito consiste na situação de que, na reparação de um produto, o fornecedor reponha neste peças já usadas, desgastadas, sem a anuência do consumidor. Isto afeta a segurança do consumidor sendo que pode comprometer o funcionamento do produto. Em um automóvel, por exemplo, a utilização de um componente usado em vez de um novo, sem o prévio consentimento do consumidor, pode resultar em acidentes de trânsito, pondo em risco não somente aquele consumidor individualizado, mas toda uma coletividade de pessoas, dado o alto grau de periculosidade conferido ao produto.

No tocante à utilização de peças não originais ou inadequadas, Antônio Herman V. Benjamin (2006) refere que se aplica, inclusive, o art. $7^{\circ}$, inciso VII da Lei 8.137/90, o qual dispõe: "Induzir o consumidor ou usuário a erro, por via de indicação ou afirmação falsa ou enganosa sobre a natureza, qualidade do bem ou serviço, utilizandose de qualquer meio, inclusive a veiculação ou divulgação publicitária [...]”. A sanção dada pelo CDC para este crime é de detenção de 3 meses a 1 ano e multa.

Ao criar estes dispositivos, o legislador teve como intuito equilibrar as relações de consumo, prezando pela transparência da publicidade, através da clareza das informações. Para tanto, o escopo da tipificação destas condutas como crimes é a proteção máxima e efetiva do consumidor, possibilitando que as informações cheguem até o sujeito hipossufuciente das relações de consumo e que estas sejam confiáveis, sendo, assim, idôneas a divulgar um bem.

Hodiernamente, a publicidade tem sido um fator decisivo para o consumidor no momento de adquirir um produto ou serviço. Por isso, o Código de Defesa do 
Consumidor o protege contra estes crimes, prevendo para tais condutas penas privativas de liberdade, além das penas de caráter pecuniário, dada a usura que tem se dado pelos fornecedores na contemporaneidade.

Tutelada a proteção penal ao consumidor, é conveniente que se esclareça qual a via que o consumidor deve percorrer para levar este conflito ao Estado e a seu respectivo órgão julgador.

\section{PROCEDIMENTOS PARA A TUTELA PENAL EFETIVA DO CONSUMIDOR}

Os crimes dispostos no CDC são todos considerados de menor potencial ofensivo, pois possuem penas de detenção não superiores a dois anos. Estes delitos deverão ser julgados pelos Juizados Especiais Criminais, conforme Lei 9099/95. O art. 81 da Lei dos Juizados Especiais dispõe sobre o procedimento da ação penal destes delitos de menor potencial ofensivo. A ação penal é pública incondicionada.

Ademais, existem os delitos contra as relações de consumo no próprio Código Penal. Entretanto, os artigos 171 e 175 não podem ser considerados de menor potencial ofensivo, pois têm pena de reclusão e o seu máximo ultrapassa 4 anos conforme a Lei 10.259/01 (Lei dos Juizados Especiais Federais). Esta lei dispõe acerca dos Juizados Especiais Criminais na esfera federal. Como bem preleciona a legislação retromencionada, para estes tribunais especiais federais, delitos com pena máxima de até 4 anos ainda são considerados de menor potencial ofensivo. Outrossim, a competência para julgar delitos os quais não se configurem de menor potencial ofensivo é da justiça comum, seja a âmbito estadual ou federal. Não obstante, existem os delitos contra a saúde pública previstos no Capítulo III, do Título VIII da Parte Especial do Código Penal. Estes, quando dolosos, serão também julgados pela justiça comum. É possível, ainda, elencar os delitos contra o consumidor previstos na legislação esparsa, tal qual a Lei 8.137/90, os quais serão, também, julgados pela justiça comum.

Para a garantia da defesa dos consumidores em juízo, o Código de Defesa do Consumidor, como microssistema que é, não descuidou de sua defesa coletiva. Isto é, quando o fato delituoso atingir um grupo de pessoas, não sendo possível determiná-las, é possível que se proponha uma ação penal pública. Isto se dá quando o direito ferido é difuso, ou seja, de natureza indivisível, sendo os titulares pessoas indeterminadas ligadas por circunstâncias de fato. A exemplo disso, pode-se referir os consumidores vítimas de uma publicidade enganosa em veiculada larga escala, divulgada em jornal de 
circulação nacional. A lei consumerista protege, ainda, e de igual forma, os direitos coletivos, possibilitando o direito de ação coletiva para um grupo determinado de pessoas ligadas por uma relação jurídica de base, a saber, a classe de moto-taxistas que adquire um modelo específico de motocicletas, as quais vêm com vício que põe em perigo a segurança deste grupo.. Em seus artigos 81 e 82, o CDC dispõe a respeito a defesa coletiva dos consumidores.

No entanto, não se pode olvidar que a sentença penal condenatória transitada em julgado faz coisa julgada no juízo cível (art. 63 do Código de Processo Penal). Isto significa que as vítimas de delitos contra as relações de consumo poderão exigir a reparação civil dos danos. No CDC, o art. 91 ampara as vítimas destes delitos os quais resultaram em sentença penal condenatória. Ademais, o art. 103 da lei consumerista preleciona acerca da coisa julgada da ação civil de reparação de danos, podendo ter efeitos ultra partes ou erga omnes. A primeira situação ocorrerá em casos de grupo determinado de pessoas que propõe a ação, quando a sentença não for improcedente por insuficiência probatória. No segundo caso, apenas não ocorrerá tal efeito se o pedido for julgado improcedente, também, por insuficiência de provas. No que tange às vítimas e seus sucessores, apenas no caso de procedência do pedido estes serão beneficiados.

\section{CONSIDERAÇÕES FINAIS}

Por derradeiro, não seria demasiado referir que os delitos contra as relações de consumo são tão graves quanto delitos de roubo, extorsão e lesões corporais. Isto somente será perceptível, ao se fazer uma leitura hermenêutica destas disposições legais. Em uma primeira leitura, poderá parecer que estes delitos ofendem somente a ordem econômica do Estado. Entretanto, se o jurista olhar as normas aqui estudadas sob as lentes da Lei Maior da República, perceberá que a proteção às relações de consumo implica em proteção aos direitos fundamentais do cidadão, os quais incluem o direito à saúde e à segurança. Em se tratando de proteção a direito fundamental, pois, a tutela penal do consumidor se faz indispensável. Deste modo, o Estado está cumprindo sua função ao resguardar tais direitos à proteção penal.

\section{REFERÊNCIAS BIBLIOGRÁFICAS}

BITENCOURT, Cezar Roberto. Tratado de Direito Penal. 9a Ed. São Paulo: Saraiva, 2004. V. 1: Parte Geral. 
BITENCOURT, Cezar Roberto; CONDE, Francisco Muñoz. Teoria Geral do Delito.

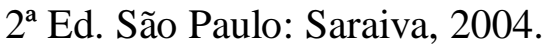

FILOMENO, José Geraldo Brito. Curso Fundamental de Direito do Consumidor. São Paulo: Atlas, 2007.

GRINOVER, Ada Pellegrini; BENJAMIN, Antônio Herman de Vasconcellos e; FINK, Daniel Roberto; FILOMENO, José Geraldo Brito; WATANABE, Kazuo; NERY JR., Nelson; DENARI, Zelmo. Código de Defesa do Consumidor Comentado Pelos Autores do Anteprojeto. 9a Ed. Rio de Janeiro: Forense Universitária, 2007.

MARQUES, Claudia Lima; BENJAMIN, Antônio Herman de Vasconcellos; MIRAGEM, Bruno. Comentários ao Código de Defesa do Consumidor. $2^{\text {a }}$ Ed. São Paulo: Revista dos Tribunais, 2006.

MORAES, Alexandre de. Direito Constitucional. 19ª Ed. São Paulo: Atlas, 2006.

NUCCI, Guilherme de Souza. Código Penal Comentado. $6^{\text {a }}$ Ed. São Paulo: Revista dos Tribunais, 2006.

NUCCI, Guilherme de Souza. Leis Penais e Processuais Penais Comentadas. $2^{\mathrm{a}}$ Ed. São Paulo: Revista dos Tribunais, 2007.

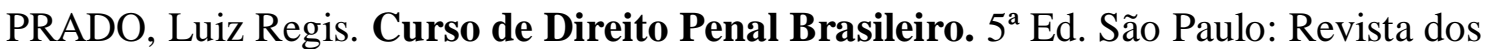
Tribunais, 2006. V. 2: Parte Especial.

SILVA, José Afonso da. Curso de Direito Constitucional Positivo. 26ª Ed. São Paulo: Malheiros, 2006. 
